\title{
ANALISIS ADIKSI INTERNET TERHADAP KEMAMPUAN INTERPERSONAL SISWA SMA DI KABUPATEN LABUHAN BATU UTARA
}

\author{
Ika Chastanti \\ Program Studi Pendidikan Biologi \\ FKIP Universitas Labuhan Batu \\ Jl. SM. Raja No. 126 A, Rantauprapat, Sumatera Utara \\ Alamat e-mail: Chastanti.ika@gmail.com
}

\begin{abstract}
Abstrak
Era globalisasi kehidupan manusia tidak bisa dilepaskan dari internet. Pemanfaatan internet digunakan masyarakat untuk mengakses media sosial sebagai sarana untuk komunikasi dan eksistensi diri. Teknologi internet dapat diakses oleh semua kalangan masyarakat. Remaja salah satu pengguna internet aktif. Penelitian ini bertujuan untuk mengetahu adiksi internet terhadap kemampuan interpersonal siswa. Penelitian ini merupakan penelitian deskriptif dengan metode survey. Sampel dalam penelitian ini adalah siswa SMA di Kabupaten Labuhanbatu Utara. Teknik sampling yang digunakan yaitu Stratified random sampling. Teknik pengambilan data dilakukan dengan memberikan angket skala likert dan wawancara mendalam kepada siswa. Teknik analisis data menggunakan Model Miles dan Huberman. Hasil penelitian menunjukkan bahwa adiksi internet pada siswa mempengaruhi kemampuan interpersonal sebesar 76,54\% siswa lebih memilih berkomunikasi melalui media sosial daripada harus berkomunikasi langsung kepada temannya. Siswa juga tidak mampu mengontrol diri untuk mengakses internet yang mana 64,73\% siswa menjawab sepanjang waktu mengakses internet sehingga menyebabkan siswa malas untuk melaksanakan kegiatan belajar baik di rumah maupun di sekolah.
\end{abstract}

Kata Kunci: adiksi internet; kemampuan interpersonal; siswa;

\begin{abstract}
The globalization era of human life cannot be separated from the internet. The use of the internet is used by the public to access social media as a means for communication and self-existence. Internet technology can be accessed by all people. Teenager, one of the active internet users. This study aims to determine internet addiction to students' interpersonal abilities. This research is a descriptive study with a survey method. The sample in this study were high school students in North Labuhanbatu Regency. The sampling technique used is Stratified random sampling. The data collection technique is done by giving a Likert scale questionnaire and indepth interviews to students. The data analysis technique uses the Miles and Huberman models. The results showed that internet addiction in students influenced interpersonal skills by $76.54 \%$, students preferred to communicate through social media rather than having to communicate directly with their friends. Students are also unable to control themselves to access the internet, where $64.73 \%$ of students answer all the time accessing the internet, causing students to be lazy to carry out learning activities both at home and at school.
\end{abstract}

Keywords: internet addiction; interpersonal skill; student;

\section{PENDAHULUAN}

Perkembangan teknologi menyebabkan dunia tanpa batas, dengan mengakses internet hampir semua kebutuhan manusia tersedia, mulai dari 
pemenuhan kebutuhan sehari-hari, bersosialisasi, mencari informasi dan kebutuhan hiburan. Pemanfaatan internet digunakan masyarakat untuk mengakses media sosial sebagai sarana untuk komunikasi dan eksistensi diri. Teknologi internet dapat diakses oleh semua kalangan masyarakat. Remaja salah satu pengguna internet aktif. Remaja cenderung mengakses internet hanya untuk sekedar chat dengan orang asing dengan menggunakan berbagai macam aplikasi.

Pengguna internet terbesar di Indonesia adalah remaja dengan rentang usia 15-24 tahun dengan prosentase 26,7\% - 30\%. Internet yang digunakan oleh remaja cenderung dalam dampak negatif (Hapsari dan Ariana, 2015). Hampir 80\% remaja berusia 10-19 tahun yang tersebar di 11 provinsi di Indonesia kecanduan internet, dan sebagian besar remaja menggunakan internet untuk hal-hal yang tidak semestinya. 24\% mengaku menggunakan internet untuk berinteraksi dengan orang yang tidak dikenal, 14\% mengakses konten pornografi, dan sisanya untuk game online dan kepentingan lainnya (Adiarsi, 2015).

Semakin banyak pengguna internet, maka akan menyebabkan kecanduan internet (Internet Addiction)). Kecanduan merupakan suatu keterlibatan secara terus-menerus dengan sebuah aktivitas meskipun hal-hal tersebut mengakibatkan konsekuensi negatif. Seseorang bisa dikatakan kecanduan internet jika penggunaannya bisa lebih dari tiga puluh menit dalam sehari atau jika dilihat dari frekuensinya maka penggunaannya bisa lebih dari tiga kali dalam sehari (Laili dan Nuryono, 2015). Kecanduan internet dapat memberikan efek samping dalam kehidupan sehari-hari siswa seperti kecemasan, depresi, penurunan fisik dan mental, serta penurunan kemampuan interpersonal yang mengakibatkan remaja tidak mampu untuk bersosialisasi dengan lingkungan sekitar.

Dampak intensitas kecanduan internet menyebabkan seseorang tidak tahu waktu, lebih mementingkan diri sendiri, malas belajar dan melakukan kegiatan lainnya, kurangnya sopan santun, enggan untuk berkomunikasi dengan dunia nyata (Sariroh, 2016). Seseorang yang kecanduan internet cenderung mengalami depresi dan menjadi individualitas karena tidak melakukan komunikasi sosial (Widiana, 2014). 
Komunikasi merupakan salah satu bentuk interaksi yang dilakukan dalam kehidupan sehari-hari,melalui komunikasi interpersonal, seseorang tidak hanya memandang lawan bicara namun juga dapat melihat motif atau ekspresi dari lawan bicara (Rakhmat, 2011). Komunikasi tatap muka dapat merangsang kepekaan seseorang terhadap orang lain, menghargai sesama, lebih mudah merasa simpati, dan melatih seseorang untuk melindungi diri sendiri dan membiasakan seseorang untuk bersikap lebih terbuka, dan memiliki empati.

Pengguna internet aktif biasanya mengabaikan pentingnya komunikasi tatap wajah. Dalam komunikasi interpersonal, paralinguistic (petunjuk verbal) menunjukkan apa yang diucapkan melalui tingi rendahnya suara, tempo bicara, gaya verbal dan interaksi, karena cara dan gaya berkomunikasi seseorang menunjukkan kepribadian, dan hal ini tidak dapat terlihat jika komunikasi yang dilakukan hanya melalui internet (Rakhmat, 2011). Berdasarkan permasalahan ini, maka tujuan penelitian ini adalah untuk mengetahui adiksi internet terhadap kemampuan interpersonal siswa.

\section{METODE}

Penelitian ini dilakukan di SMA Negeri di Kabupaten Labuhanbatu Utara dengan teknik sampling Stratified random sampling. Sampel pada penelitian jni adalah siswa yang berjumlah 100 orang. Pengumpulan data dilakukan dengan metode survey yaitu dengan memberikan angket menggunakan skala likert untuk mengetahui tingkat adiksi internet pada siswa. Penelitian ini berupa kuantitatif dengan penyajian deskriptif.

\section{HASIL DAN PEMBAHASAN}

Hasil analisis angket adiksi internet menunjukkan bahwa intensitas waktu siswa mengakses internet sebesar 68,90\% menjawab selalu, ketidakmampuan kontrol diri 64,73\% menjawab selalu, dan mengabaikan kehidupan sosial 76,54\% menjawab selalu (Gambar 1). 


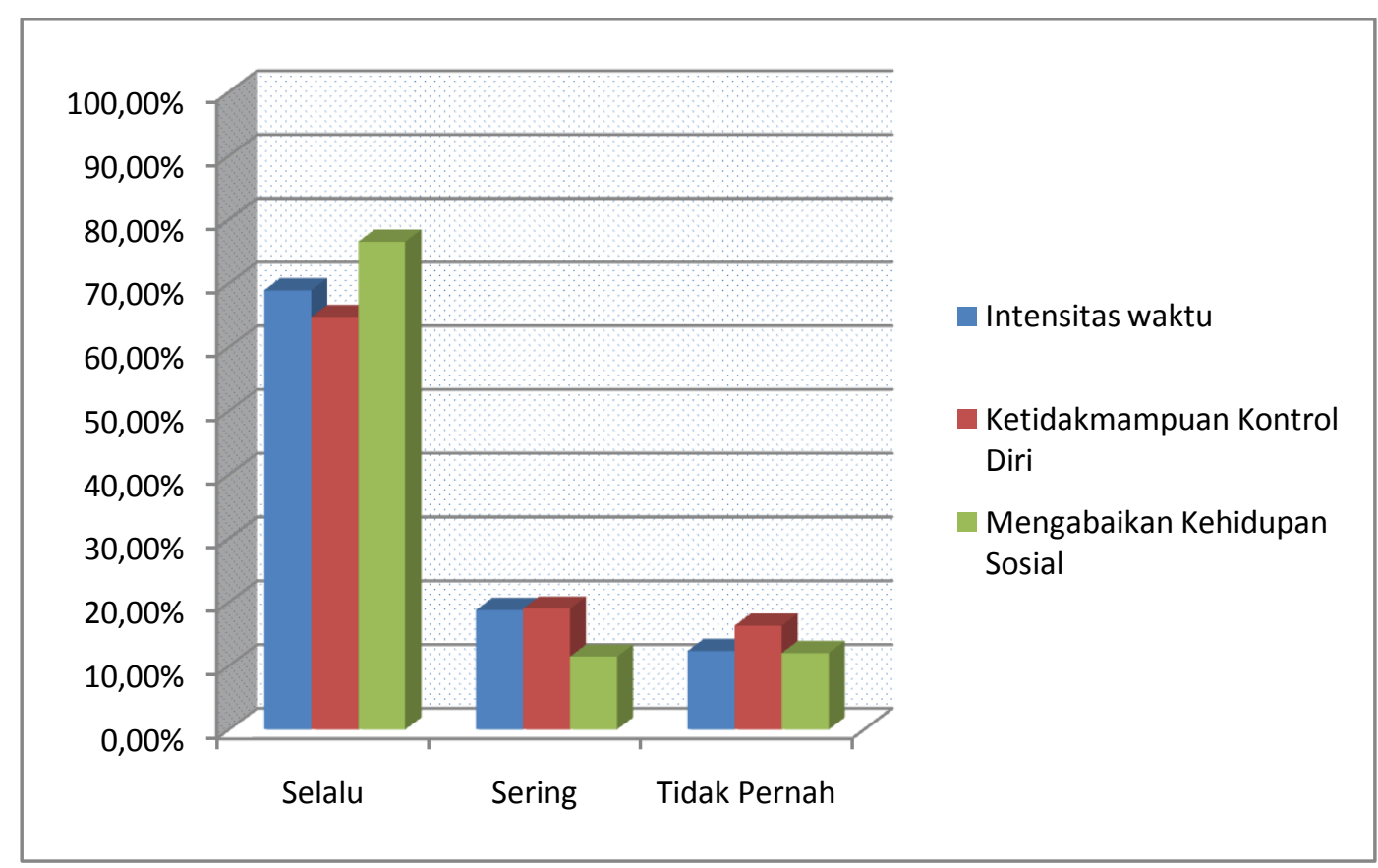

Gambar 1. Adiksi Internet pada siswa

Hasil menunjukkan bahwa penggunaan waktu siswa lebih intens dalam mengakses internet. Siswa biasanya selalu membuka akun media sosial hanya untuk membaca status temannya di media sosial. Hasil wawancara dengan siswa diperoleh bahwa intensitas waktu siswa mengakses media sosial sepanjang waktu dan ada juga yang mengakses 6 jam setiap harinya. Ini menunjukkan bahwa siswa sudah kecanduan terhadap penggunaan internet hingga membuat siswa tidak melakukan kegiatan agar bisa mengakses internet. Kecanduan internet secara berlebihan dapat membuat si pengguna tidak mampu mengontrol penggunaannya. Siswa yang secara berlebihan dalam kegiatan online akan merasa bahwa aplikasi internet lebih menarik dibandingkan kehidupan nyata yang nantinya akan mengganggu kehidupan sosial sehingga menyebabkan kemampuan interpersonal siswa akan menurun.

Adiksi internet yang berlebihan dapat memberikan perilaku negative bagi penggunanya sehingga bisa merugikan bagi diri sendiri dan juga bagi lingkungan sosial. Contoh perilaku negatif dari adiksi internet adalah mengabaikan pekerjaan baik di rumah maupun di sekolah, siswa lebih memilih untuk membuka media sosial daripada harus belajar. Hasil wawancara menujukkan bahwa siswa selalu 
membuka notifikasi dari media sosial walaupun pesan yang diterima bersifat tidak penting. Adiksi internet pada aspek kemampuan control diri menunjukkan bahwa siswa sulit untuk membagi waktu antara dunia nyata dengan dunia maya dan siswa biasanya lebih boros untuk membeli paket internet agar bisa mengakses internet. Siswa lebih sering untuk update status di media sosial demi menunjukkan eksistensinya di dunia maya. Adiksi internet pada aspek mengabaikan kehidupan sosial menunjukkan bahwa siswa selalu lupa ada teman di sebelahnya jika sedang mengakses internet. Siswa juga lebih sering aktig untuk chatting di grup media sosial daripada berbicara langsung dengan temannya.

\section{Adiksi Internet dalam Penggunaan Waktu}

Individu yang memperlihatkan gejala kecanduan internet akan mengarah pada masalah mental emosional, di antaranya dapat menyebabkan distorsi waktu, kurang perhatian, hiperaktif dan lain sebagainya (Fitri et.al., 2018) Selanjutnya, dari hasil penelitian Brenner, 80\% dari 600 responden menunjukkan setidaknya ada lima masalah yang berhubungan dengan penggunaan internet, seperti kegagalan untuk mengatur waktu, tidak tidur, tidak makan dan lain-lain. Jadi, time management problem merupakan masalah yang dialami individu untuk mengatur waktu saat menggunakan internet.

Seseorang merasa tertarik untuk mengakses internet karena mendapatkan kepuasaan ketika mengaksesnya seperti mempermudah komunikasi dengan teman atau keluarga yang jaraknya jauh, bahkan untuk menambah wawasan dan pengetahuan umum. Keinginan untuk mengakses internet terus menerus dapat menyebabkan Internet Addiction sehingga akhirnya bisa merasakan dampak negatifnya (Hakim dan Raj, 2017). Siswa rata-rata mengakses internet lebih dari 6 jam per harinya, sehingga siswa tidak pernah berhenti untuk mengakses internet. Siswa kecanduan dengan akun media sosial sehingga tidak ada keingin untuk berhenti.

Dampak negatif yang dirasakan akibat dari adiksi internet ketika menggunakannnya secara terus menerus adalah ketika Offline akan merasa gelisah, cemas, bingung, bosan dan kesal hati. Kesibukan yang dilakukan saat Offline 
adalah tidur sehingga menyebabkan seseorang tidak akan produktif. Ketika Online perasaan si pengguna akan lebih tenang, senang, dan bahagia karena bisa melihat informasi terbaru dan merasa tidak ingin berhenti untuk terus melihat dan menonton video yang disukai di internet. Terdapat hubungan penggunaan waktu dengan control diri yang mana biasanya siswa akan sulit untuk mengontrol diri ketika merasa nyaman untuk mengakses internet. Semakin tinggi kecanduan internet maka semakin rendah control diri. Besarnya sumbangan efektif yang diberikan oleh variabel control diri untuk kecanduan internet adalah 17,8\% ( Arisandy, 2009).

Kecanduan pada remaja ini harus dientaskan, jika tidak maka akan membawa dampak buruk untuk perkembangan remaja kedepannya. Remaja merupakan salah satu pengguna internet yang justru belum mampu memilah aktivitas internet yang bermanfaat, mereka cenderung mudah terpengaruh oleh lingkungan sosial tanpa mempertimbangkan terlebih dahulu efek positif atau negatif yang akan diterima saat melakukan aktivitas internet (Qomariyah, 2013).

\section{Adiksi Internet Terhadap Kemampuan Interpersonal}

Seseorang dengan kecanduan internet akan kesulitan mengembangkan kemampuan atau kecakapannya dalam berhubungan dengan orang lain sehingga membuat hubungan sosial dan interaksi mereka dengan keluarga, teman dan orang disekitarnya menjadi kurang baik serta mengalami prestasi akademik yang menurun. Seseorang bisa menderita adiksi internet dan mengalami gejala-gejala withdrwal bila menghentikan kegiatan tersebut. Akibat adiksi ini akan menimbulkan fungsi hubungan sosial lainnya (Dewi, 2011).

Manusia merupakan makhluk sosial yang dalam kesehariannya senantiasa bekerja sama dengan manusia lainnya. Kemampuan psikososial penting dimiliki oleh manusia yang meliputi percaya diri, kontrol diri, kemampuan kerjasama, kemudahan bergaul, kemampuan konsentrasi, empati, dan kemampuan komunikasi (Ikhwanuddin, 2011). Kecanduan internet berpotensi melumpuhkan kepribadian individu. Individu yang sebenarnya mampu berin-teraksi dengan baik dalam dunia nyata cenderung memilih berinteraksi melalui dunia maya karena kenyamanan 
yang ditawarkan. Akibatnya, kemampuan indi-vidu untuk berinteraksi dan bersosialisasi menjadi tumpul (Young, 1998).

Penggunaan internet yang berlebihan dapat mengakibatkan terjadinya masalah pribadi, keluarga dan pekerjaan. Pemanfaatan internet yang berlebihan mengakibatkan hubungan dengan teman dan keluarga menjadi renggang karena waktu yang digunakan untuk kumpul bersama menjadi jauh berkurang, sehingga remaja menjadi terisolir dari teman-teman dan keluarganya, serta menjadi sulit berkonsentrasi terhadap pelajaran di sekolah. Jadi, interpersonal dan health problem merupakan permasalahan yang dapat terjadi antara diri individu maupun dengan orang lain (Sari et.al., 2018).

\section{SIMPULAN}

Adiksi internet pada siswa memberikan pengaruh terdahap intensitas waktu dengan persentase $68,90 \%$ menjawab selalu mengakses internet sepanjang waktu, internet juga memberikan pengaruh terhadap control diri sebesar $64,73 \%$ siswa menjawab bahwa ketika mengakses internet maka siswa cenderung mengabaikan belajar dan boros dalam pemakaian paket internet, adiksi internet menyebabkan kemampuan interpersonal $76,54 \%$ siswa lebih memilih komunikasi di grup media sosial dibandingkan berkomunikasi langsung dengan menatap wajah temannya.

\section{DAFTAR PUSTAKA}

Adiarsi, G. R., Stellarosa, Y., \& Silaban, M. W. (2015). "Literasi Media Internet Dikalangan Mahasiswa". HUMANIORA Vol.6 : (4).

Dewi, N. (2011). "Hubungan Kecanduan Internet dan Kecemasan dengan Insomnia pada Mahasiswa S1 FK UNS yang sedang Skripsi". Tesis. Fakultas Kedokteran Universitas Sebelas Maret Surakarta.

Hakim, S.N., Raj A.A. (2017). "Dampak Kecanduan Internet (Internet Addiction) pada Remaja". Prosiding Temu Ilmiah $X$ Ikatan Psikologi Perkembangan Indonesia. Semarang.

Hapsari, A., \& Ariana, A. D. (2015). "Hubungan antara Kesepian dan Kecenderungan Kecanduan Internet pada Remaja". Jurnal klinis dan kesehatan mental, 164-171. 
Ikhwanuddin. (2011). Implementasi pendi-dikan karakter kerja keras dan kerja sama dalam perkuliahan. Yogyakarta: UNY.

Qomariyah, A. N. (2013). "Perilaku Penggunaan Internet pada Kalangan Remaja di Perkotaan". https://doi.org/10.1017/CBO9781107413254.004.

Sari, A.P., Ilyas A., Ifdil. (2017). "Tingkat Kecanduan Internet pada Remaja Awal". Jurnal Penelitian Pendidikan Indonesia. Vol. 4 : (2). Hlm. 110 -117.

Widiana, H.S, Retnowati, S., Hidayat. R. (2004). "Kontrol Diri dan Kecenderungan Kecanduan Internet". Jurnal Humanitas: Indonesian Psychologycal Journal. Vol. 5: (1). Hlm. 6 - 16.

Young, K.S. (1998). "Internet addiction: The emergence of a new clinical disorders". CyberPsychology \& Behavior, 1(3). doi: 10.1089/cpb.1998.1.237. 